\title{
Staggered Boards and Shareholder Value: A Reply to Amihud and Stoyanov
}

\section{Citation}

Cohen, Alma, and Charles CY Wang. "Staggered Boards and Shareholder Value: A Reply to Amihud and Stoyanov." Harvard Business School Working Paper, No. 16-097, February 2016.

\section{Permanent link}

http://nrs.harvard.edu/urn-3:HUL.InstRepos:25680333

\section{Terms of Use}

This article was downloaded from Harvard University's DASH repository, and is made available under the terms and conditions applicable to Open Access Policy Articles, as set forth at http:// nrs.harvard.edu/urn-3:HUL.InstRepos:dash.current.terms-of-use\#OAP

\section{Share Your Story}

The Harvard community has made this article openly available.

Please share how this access benefits you. Submit a story.

\section{Accessibility}




\title{
Staggered Boards and Shareholder Value: A Reply to Amihud and Stoyanov
}

\author{
Alma Cohen
}

Charles C.Y. Wang

Working Paper 16-097 


\title{
Staggered Boards and Shareholder Value: A Reply to Amihud and Stoyanov
}

\author{
Alma Cohen \\ Tel-Aviv University \\ Charles C.Y. Wang \\ Harvard Business School
}

Working Paper 16-097 


\title{
Staggered Boards and Shareholder Value: A Reply to Amihud and Stoyanov
}

\author{
Alma Cohen and Charles C.Y. Wang ${ }^{*}$
}

\begin{abstract}
$\underline{\text { Abstract }}$
In a paper published in the JFE in 2013, we provided evidence that market participants perceive staggered boards to be on average value-reducing. In a recent response paper, Amihud and Stoyanov (2015) "contest" our results. They advocate using alternative methods for estimating risk-adjusted returns and excluding some observations from our sample. Amihud and Stoyanov claim that making such changes renders our results not significant (though retaining their direction) and conclude that staggered boards have no significant effect on firm value. This paper examines and replies to the Amihud-Stoyanov challenge. We question their methodological claims, study the consequences of following their suggestions, and conduct additional robustness tests. Our analysis shows that the evidence is overall consistent with the results and conclusions of our JFE paper.
\end{abstract}

Keywords: Corporate governance; Staggered boards; Takeover defense; Antitakeover provision; Firm value; Agency costs; Delaware; Chancery court; Airgas.

JEL Classification: G30, G34, K22

\footnotetext{
* Harvard Law School, NBER, and Tel-Aviv University, and Harvard Business School, respectively.
} 
In a paper published in the JFE in 2013, "How Do Staggered Boards Affect Shareholder Value? Evidence from a Natural Experiment" [Cohen and Wang (2013, hereinafter "CW")], we provided evidence that market participants perceive staggered boards to be on average valuereducing. In a response paper, titled "Do Staggered Boards Harm Shareholders?" Amihud and Stoyanov (2015) (hereinafter "AS") set out to "contest" our results. They argue for using alternative methods for estimating risk-adjusted returns and for excluding some observations from the $\mathrm{CW}$ sample. Based on a subsample that reflects the exclusion of certain observations, they report results that are in the same direction as $\mathrm{CW}$ but are not statistically significant. This paper examines and replies to the AS challenge.

Below we question the methodological suggestions made by AS and explain that they are unwarranted or at most debatable. Nonetheless, we analyze in detail the empirical consequences of following the suggestions of Amihud and Stoyanov, and we also conduct additional robustness tests. Our analysis demonstrates that the evidence is overall consistent with the conclusions of $\mathrm{CW}$.

The paper is organized as follows. Section I begins by describing our results and the AS challenge. Section II shows that our results are robust to using an alternative method for inferring excess returns that AS advocate as commonly used, but that was not implementable immediately following the rulings when we commenced our work on the JFE paper. Section III examines the consequences of excluding observations in the various ways suggested by AS. Section IV presents results examining the consequences of such exclusions of observations under an alternative definition of treated firms. Although we explain that there are reasons not to base tests on the precise subsample advocated by AS, Section V considers this precise subsample. Section VI provides our conclusion.

\section{Our Results and the Amihud-Stoyanov Challenge}

It is well-documented that staggered boards are associated with lower firm value as measured by Tobin's Q. ${ }^{1}$ Correlation, however, does not imply causation, and our JFE paper

\footnotetext{
${ }^{1}$ See, e.g., Bebchuk and Cohen (2005), Faleye (2007), Frakes (2007), Bebchuk, Cohen, and Ferrell (2009). Recently, Cremers, Litov and Sepe (2014) claimed that using firm fixed effects regressions
} 
sought to contribute to the literature by examining whether staggered boards lead to lower firm valuation.

This question has policy significance. Substantial shareholder preference for annual elections has been registered over the last fifteen years. Major institutional shareholders, as well as the leading proxy advisors, have all adopted policies in favor of de-staggering boards. In response to shareholders' registered preferences, many companies have moved to a unitary board structure. Still, despite the substantial support among shareholders for declassification, some issuers and their advisors continue to support staggered boards, and the debate continues to go on in the marketplace.

To study the effect of staggered boards on shareholder value, we took advantage of a quasi-experimental setting arising from two Delaware court rulings regarding the takeover battle between Airgas Inc. and Air Products Chemicals, Inc. These rulings focused on the permissibility of shareholder-adopted bylaw amendments that substantially weaken the antitakeover force of staggered boards for those firms with annual shareholder meetings taking place in the later part of the year (but not those firms whose meetings take place in the first few months of the year). In the initial ruling, issued on October 8, 2010, the Delaware Chancery Court ruled that such shareholder-adopted bylaw amendments are permissible. On November 23, 2010, however, the Delaware Supreme Court reversed the lower court ruling and held such amendments to be invalid. Our identification strategy relies on the assumption that both rulings were at least partly unanticipated, and that the choice of "early" versus "late" shareholder meetings is essentially random, or at least not otherwise correlated with returns during the two event windows, across firms within the same industry.

We began working on this project shortly after the two events that are the subject of the JFE paper. We began by collecting governance data, in particular data on annual meeting dates and the presence of staggered boards, from Factset's SharkRepellent, for the cross section of firms that were classified as trading on a primary exchange. We limited our analyses to the subsample of firms for which we were able to find a match to a historical CRSP permno

reverses the cross-sectional results and indicates that staggered boards are value-increasing, but one of us and Lucian Bebchuk explain in current work-in-progress that the Cremer-Litov-Sepe claim is unwarranted. 
identifier and Compustat gvkey identifier. Finally, because stock returns data around the days of the rulings were at the time unavailable on the Center for Research in Security Prices (CRSP), we merged into our SharkRepellent sample returns data from Datastream.

Moreover, because we did not have Fama-French factors' returns for the dates around the rulings, we employed a method for inferring excess returns that did not rely on factors' returns data during this period. In particular, we computed risk-adjusted excess returns in two steps (see pages 633-634 of our JFE for detailed description). The first step is the standard procedure for estimating each firm's factor loadings on the Fama-French three factors and the momentum factor, using the most recently available 120 trading days' data ending on or prior to September 30, 2010. In the second step, we obtain excess announcement window returns by taking the residuals from the cross-sectional regression of the raw announcement window returns on the estimated factor sensitivities, where our cross-section data included all the firms in our SharkRepellent-Datastream intersection.

Our empirical analysis focused on the differences in excess announcement returns between (i) those firms with staggered boards that can be expected to be most affected by the rulings - Delaware firms with a staggered board and an annual meeting in the later part of the year (September to December) - and (ii) those firms with staggered boards that were expected to be least affected by the rulings - Delaware firms with a staggered board and an annual meeting in the early part of the year (January to March). Both types of firms have their annual meetings "off season" - taking place either after or before the April-to-June period, during which most firms have their annual meetings. Our analysis also excludes REITs, firms with dual-class shares, and firms with majority insider ownership. The resultant sample considered by the JFE paper consists of 139 total firms, of which 77 are classified as treated and 62 are classified as controls.

We focused our analyses on comparing early- and late-meeting firms that have staggered boards because, as we argued in our paper (p. 633), firms with and without staggered boards could be substantially different along several dimensions. Thus, the comparison of staggered versus non-staggered firms could obfuscate inferences from observed differences in announcement period returns (for example, if other news in the day affected some firm types that are correlated with the choice of staggered boards). Moreover, we focus on a comparison within the same (GICS6) industry to account for the possibility that there could be industry-specific 
news that confounds our analyses. ${ }^{2}$ In other words, our identification strategy assumes that the treatment status - whether a firm in an industry is early- or late-meeting - is practically "as good as random" or is at least unconfounded (see page 634 of $\mathrm{CW}$ and footnote 22 for a detailed discussion of our identification strategy). Note in this connection that both the early-meeting and late-meeting firms are similar in that both types have meetings that are "off-season," and that the meeting-date classification is pre-determined.

Table 1, column (1) in Panel A presents the main result of CW. Observations from both events are integrated in one regression, by multiplying the excess returns around the second ruling by -1 . We then estimate a pooled regression of the 2-day excess returns (in basis points) on a treatment group indicator (Treat) and an indicator for the second event date (Event II). We find, as in CW Table 1 column (2), differential abnormal announcement returns of 96.12 basis points, which is significant at the $10 \%$ level.

In Panel B, we present the results of the alternative method used by $\mathrm{CW}$ for assessing the statistical significance of these results. In particular, following $\mathrm{CW}$, we examine how common it is over a sample of non-event days to observe treatment effects (i.e., differences in excess returns between late- and early-meeting firms) that are large and positive on one day and large and negative on another. To facilitate this analysis, we simulate a bivariate distribution over pairs of non-event days from January to June of 2010 of treatment coefficients obtained from regressions of excess returns on the treatment indicator. Based on this simulated distribution, we conclude that it is quite unlikely - occurring in less than $0.6 \%$ of the time - for both the first event to produce a treatment coefficient of 82.82 basis points or higher and the second event date to produce a treatment coefficient of -109.41 basis points or lower.

\footnotetext{
${ }^{2}$ Amihud and Stoyanov criticize our use of GICS6 and advocates using GICS4. However, using GICS6 enables making sharper comparisons and is supported by studies such as Bhojraj, Lee, and Oler (2003). Furthermore, while some of our observations do not have industry peers using GICS6, this does not distort out results, as they are essentially eliminated from the estimation, and thus only makes it more difficult to obtain significance.
} 
Table 1

\begin{tabular}{lcc}
\hline \hline Panel A: Pooled & $(1)$ & \\
& Method 1 & $(2)$ \\
\cline { 2 - 3 } Treat & $96.12^{*}$ & Method 2 \\
\cline { 2 - 3 } & $(51.3)$ & $95.05^{*}$ \\
Event II & 17.35 & $(53.2)$ \\
& $(45.8)$ & 35.73 \\
Cons & -42.54 & $(45.2)$ \\
& $(46.1)$ & -48.18 \\
$\mathrm{~N}$ & & $(45.9)$ \\
\end{tabular}

Panel B: Individual Days vs. Simulation

$\begin{array}{llr}\text { Event } 1 & 82.82 & 85.622\end{array}$

Event $2-109.41 \quad-104.468$

\begin{tabular}{lcc}
$p$-Value & $0.0060 * * *$ & $0.0092 * * *$ \\
\hline \hline Note: Treat is a treatment firm indicator (whose shareholder meetings take place between
\end{tabular}

September and December) and Event II is an indicator for the second event date. Second event returns are multiplied by -1. GICS6 fixed effects are included. Cluster-robust standard errors, clustered at the six-digit GICS level, appear immediately below the coefficient estimates in parentheses. Levels of significance are indicated by *,**, and *** for $10 \%$, 5\%, and 1\%, respectively.

We should note that our findings that market participants perceive staggered boards to be value-decreasing is consistent with the findings of three other related event studies based on exogenous shocks. Karakas and Mohseni (2015) study the same two rulings in the Airgas case that we examine, find that the weakening of staggered boards was accompanied by an increase in control premiums estimated from option prices, and interpret this finding to be consistent with "the entrenchment view on staggered boards." Furthermore, Kim (2015) studies the market reactions to legislations in Indiana (2009), Oklahoma (2010), and Iowa (2011) that compelled firms to adopt staggered boards, and provides evidence consistent with staggered boards being value-reducing. The results of Kim (2015) are consistent with and reinforce the conclusions of Daines (2001), which found that market prices responded negatively to the 1990 Massachusetts 
legislation that imposed a staggered board structure on all Massachusetts firms without such a structure. $^{3}$

Despite the relevance of these papers to the Amihud-Stoyanov claim regarding the value implications of staggered boards, their paper does not engage with these studies or cite them in the paper's detailed review of studies on the value effect of staggered boards. Rather, Amihud and Stoyanov seek to justify their conclusion that staggered boards have "no significant effect on firm performance and value" on two grounds. First, most of the AS analysis is dedicated to attempting to identify changes in estimation techniques or sample definition that would attenuate the significance of our results. Note that although AS seem to assert that they do not obtain significant results using the $\mathrm{CW}$ sample, their results are not based on the original sample but rather a subsample that reflects the exclusion of certain observations. Thus what their analysis purports to show is that the changes advocated by AS renders CW's results not significant (though retaining their direction), and they conclude that staggered boards have no significant effect on firm value. Below we will focus on and respond to this main part of their analysis. ${ }^{4}$

Second, Amihud and Stoyanov seek to buttress their conclusion by supplementing their criticism of our results regarding the Airgas rulings with an analysis, unrelated to the Airgas rulings, of how ROA changed in companies following board destaggerings (i.e., moves to a unitary board structure). In particular, Amihud and Stoyanov report that they find no association between destaggering and subsequent changes in ROA. This AS attempt to make inferences about the value effect of staggered boards from what happens to firms that destagger is similar in approach to (although different in results from) three studies that focus on the changes in valuation or performance following changes in staggered board status (staggering up or destaggering): (1) Cremers, Litov, and Sepe (2014), who report that destaggering is associated with subsequent declines in Tobin's Q; (2) Ge, Tanlu and Zhang (2015), who find that destaggering is associated with a subsequent reduction in ROA, in contrast to the AS finding of

\footnotetext{
${ }^{3}$ Also consistent with the view that staggered boards are value-decreasing are studies, such as Masulis et al. (2007), that show that staggered boards are associated with some value-decreasing corporate decisions. ${ }^{4}$ Our analysis and the AS criticism of it is based on the large sample of firms for which staggered boards data is available on SharkRepellent. AS also redo their tests on a sample of firms for which staggered boards data is available on the ISS dataset. The ISS sample is largely contained in the SharkRepellent sample, and is substantially smaller in size than the SharkRepellent sample. We therefore based our JFE paper, and similarly focus this paper, on the SharkRepellent dataset.
} 
no association; and (3) Guo, Kruse, and Nohel (2008), who report that destaggering is associated with positive abnormal stock returns.

The problem with this line of work, including the Amihud-Stoyanov results concerning the association between destaggering and subsequent economic outcomes, is that destaggering is not exogenous and might well reflect factors and conditions that influence or are correlated with such subsequent economic outcomes. Valid inferences concerning the value effect of staggered boards thus cannot be easily drawn from analyzing the association of destaggering with subsequent economic outcomes. Thus, the AS attempt to justify their position using such an analysis is unwarranted and, in any event, this attempt could not contribute to the ongoing debate given the aforementioned prior work on the subject. Below we will therefore focus on their attempt to weaken the significance of the results in our JFE paper.

Before proceeding, we should note that the AS assertion that staggered boards have "no significant effect on firm performance and value" is inconsistent not only with the conclusions of our JFE paper and the event studies using exogenous shocks noted above, but also with the claims of other critics of this line of work. Other critics, such as Cremers et al. (2014) claim to have evidence that suggests that staggered boards are on average value-increasing. Indeed, the view that staggered boards are value-relevant, whether they are positive or negative, seems to be widely shared by both supporters and critics of board classification. AS challenge this widely shared view but, as shown below, do not provide a solid basis for this broad challenge.

\section{Alternative Estimation of Risk-Adjusted Returns}

When Amihud and Stoyanov first contacted us in 2013 to contest our results, they faulted us for our method of estimating abnormal stock returns (labeled Method 1 below) and suggested that a standard method should be applied. We explained to them that the use of our method was dictated by the data that was available when we began our study. However, to allay their concerns, we took the time to redo our analysis using their preferred method. This method (labeled below and in their paper as Method 2), which Amihud and Stoyanov describe as commonly-used, infers expected daily stock returns to be the risk free rate plus the inner product 
between the estimated factor sensitivities for a given stock with the event-date factor returns, and cumulates the excess returns over the two-day event windows.

We agree with AS that Method 2 is the more standard and commonly-used method, and Method 1 was used in CW only because when we began the project, the data required for applying Method 2 was not available. Below we therefore focus on, and estimate all specifications both in this section and subsequent ones, using Method 2. As we show in Table 1, using Method 2 produces results that are practically identical to those produced by using Method $1^{5}$

To examine the robustness of our original results to using Method 2, we re-estimated our excess returns using the now-available data on factors' returns around the event dates. To begin, we found a correlation of 0.9906 between the excess returns obtained using Method 1 and 2 . Given this level of correlation, we do not expect our findings to be sensitive to the choice between these methods. Nonetheless, in Table 1 we rerun our main analysis using the excess returns obtained from Method 2, and compare the results to those obtained using Method 1, the methodology employed in CW.

Column (2) of Table 1 presents the results we obtain from regressing 2-day cumulative abnormal returns (CAR) around the event days on an indicator for treated firms and an indicator for the second event date. As before, we multiply the second-event CAR by -1 . Not surprisingly, our results produced by using Method 2 are nearly identical to those produced using Method 1, reported in Column (1). We also performed the simulation exercise using Method 2, and the results (see Panel B) again produce results that are practically identical both in their magnitude and statistical significance to those obtained in our JFE paper using Method 1.

\footnotetext{
${ }^{5} \mathrm{AS}$ also use another method that is not standard for event studies, and we did not take the time to redo our results using this method.
} 


\section{Removing Observations}

After we reported to Amihud and Stoyanov in 2013 that our results are robust to their preferred method for estimating abnormal returns, they subsequently turned to examine whether it might be possible to weaken the significance of these results by eliminating some observations from the sample on which our empirical analysis is based. Our event study has a small number of treated firms, and in such a small-scale study it might be possible to identify a small number of observations whose removal would affect results. Below we question the various reasons that AS give for removing observations but, for completeness, we also subsequently examine how results would be affected by each of the advocated removals of observations.

AS would like to remove observations from the sample of treated firms for four different reasons:

- Firms that received M\&A offers ("DPTI" and "ARST"): AS argue for removing two firms that were identified by AS to be ones that earlier received an M\&A offer. The potential argument for removal is that, to the extent that the acquisition was expected to be completed with absolute certainty at the time of the rulings, the stock prices of these companies could not have been expected to be affected by the court rulings. However, acquisition offers do not always result in an acquisition, and the value of the current governance provisions might thus be relevant even when an offer is outstanding. We note that the many studies that have examined the effects of staggered boards did not attempt to remove from the sample firms that had an outstanding M\&A offer at the time that value was measured. Thus, the merits of the removal of the two firms advocated by AS are debatable. However, we will examine below the consequences of such removal below.

- Firms that had an outstanding hostile tender offer (Airgas "ARG”): The argument for removing this observation is that the effect of the rulings on this observation reflects not only the market's perceptions about the general effect of a staggered board outside the context of a specific takeover situation, but also their views on the direct effect of the rulings on the specific takeover situation that this company faced. We 
note, however, that such a direct effect - i.e., the effect of staggered boards on the results of a hostile takeover - is part of the overall effect of staggered boards. We further note that prior studies have not attempted to eliminate from the sample firms that had an outstanding hostile offer at the time that value was measured. Thus, the claim of AS that ARG should be removed can be questioned, but we shall below examine its consequences below.

- Firms whose returns on the days of the rulings were very large in size ("ASB" and "EONC"): In any event study, although researchers often do not conduct such an analysis, it is likely that an analysis of all media items and SEC filings would identify firms whose large event date returns are likely attributable to major idiosyncratic news rather than to the treatment that is the focus of the study. The working premise is that the various idiosyncratic news wash out and that the remaining signal reflects the market's response to the treatment under consideration. AS identified one firm (“ASB”) whose return was large and negative on November 24 (the largest negative return during the second event window), due to an idiosyncratic effect (it was delisted) and argue that this observation should be removed from the sample at least on the day with this large negative return. In our view, to the extent that one engages in such exercise of identifying observations with large returns due to idiosyncratic shock, such an exercise should not be conducted in a selective way that focuses only on large returns in one direction. Our sample includes another firm with a return of a large size - EONC which had a return of $+15 \%$ on November 24 (the largest positive return during the second event window). In the same way that the $-40 \%$ return of ASB was unlikely to reflect the perceived effects of the second ruling, the positive $15 \%$ return of EONC is also unlikely to be caused by the rulings. Thus, if one were to go down the route of removing observations with extreme returns likely to be caused by unrelated news, it would make sense to remove both ASB and EONC. Below we examine the consequences of removing ASB and EONC. In addition, we also examine the consequences of removing from our sample observations with the top and bottom 1 percentile of returns on each event date. 
- Firms that became OTC stocks recently ("DISK". "ORXE", "ATGN"): AS identified three firms that delisted some time during the months preceding the rulings, and advocated the removal of these three firms. However, these are real firms whose stock price could have been affected by the rulings, and the case for removing them is debatable. Still, for completeness, we also examine below the consequences of removing these firms.

Table 2 below reports the results of our analysis of the consequences of removing observations from the sample. Column (1) replicates Table 1, column (2), which utilizes the whole sample used by CW. Columns (2) through (7) report the results using the same specification when we remove certain observations: column (2) removes the two firms that had outstanding acquisition offers (DPTI and ARST); column (3) removes the firm that had an outstanding hostile tender offer (ARG); column (4) removes the two firms with extreme stock returns likely reflecting idiosyncratic changes unrelated to the treatment (ASB and EONC); column (5) removes the top and bottom $1 \%$ of returns in each event window; column (6) removes all observations removed in columns (2) through (5). Finally, although we view such removal as unwarranted, in column (7) we report results based on removing, in addition to the firms removed in column (6), the three firms that belonged to Datastream but no longer to CRSP as of the first event (DISK, ORXE, ATGN).

These results indicate that, despite some sensitivity, the estimated coefficients on Treat are in all specifications in the same direction as in $\mathrm{CW}$ and largely retain statistical significance at the $10 \%$ level in standard regression-based tests. Moreover, our simulation results suggest that, in all specifications, the observed pair of treatment effects over the two event windows are very unlikely. In all cases there is less than 5\% likelihood (and in most cases less than $1 \%$ likelihood) of observing the first-day treatment effect as large and positive as what we find and a second-day treatment effect as large and negative as what we find. 
Table 2: Removing Observations

\begin{tabular}{|c|c|c|c|c|c|c|c|}
\hline Panel A: & $\begin{array}{l}\text { oled } \\
\qquad(1) \\
\text { Baseline }\end{array}$ & $\begin{array}{l}(2) \\
\text { M\&A } \\
\text { Firms }\end{array}$ & $\begin{array}{c}(3) \\
\text { ARG }\end{array}$ & $\begin{array}{c}(4) \\
\text { ASB\& } \\
\text { EONC }\end{array}$ & $\begin{array}{c}(5) \\
\text { Top \& } \\
\text { Bottom 1\% }\end{array}$ & $\begin{array}{c}(6) \\
(2)-(5)\end{array}$ & $\begin{array}{c}(7) \\
(6)+\mathrm{DS} \\
\text { Firms }\end{array}$ \\
\hline Treat & $\begin{array}{c}95.045 * \\
(53.22)\end{array}$ & $\begin{array}{c}94.754 * \\
(53.39)\end{array}$ & $\begin{array}{l}83.573^{\mathrm{a}} \\
(55.45)\end{array}$ & $\begin{array}{c}86.604^{*} \\
(51.20)\end{array}$ & $\begin{array}{c}94.358^{* *} \\
(35.53)\end{array}$ & $\begin{array}{c}84.462 * * \\
(39.58)\end{array}$ & $\begin{array}{c}61.916^{*} \\
(35.58)\end{array}$ \\
\hline Event II & $\begin{array}{l}35.729 \\
(45.20)\end{array}$ & $\begin{array}{c}34.66 \\
(45.83)\end{array}$ & $\begin{array}{l}33.869 \\
(45.64)\end{array}$ & $\begin{array}{c}17.46 \\
(29.40)\end{array}$ & $\begin{array}{l}17.692 \\
(27.35)\end{array}$ & $\begin{array}{l}11.421 \\
(28.41)\end{array}$ & $\begin{array}{c}12.68 \\
(27.50)\end{array}$ \\
\hline Cons & $\begin{array}{l}-48.182 \\
(45.88)\end{array}$ & $\begin{array}{l}-47.512 \\
(45.92)\end{array}$ & $\begin{array}{l}-43.64 \\
(47.01)\end{array}$ & $\begin{array}{l}-40.599 \\
(36.28)\end{array}$ & $\begin{array}{c}-51.052 * * \\
(24.68)\end{array}$ & $\begin{array}{c}-44.246^{*} \\
(26.03)\end{array}$ & $\begin{array}{c}-37.821 \mathrm{a} \\
(23.45)\end{array}$ \\
\hline Ind FE & Yes & Yes & Yes & Yes & Yes & Yes & Yes \\
\hline $\mathrm{N}$ & 278 & 274 & 276 & 274 & 270 & 262 & 258 \\
\hline
\end{tabular}

Panel B: Individual Days vs. Simulation

\begin{tabular}{|c|c|c|c|c|c|c|c|}
\hline Event 1 & 85.622 & 85.657 & 78.485 & 89.974 & 102.822 & 100.601 & 87.179 \\
\hline Event 2 & -104.468 & -103.850 & -88.662 & -83.233 & -79.962 & -62.032 & -34.085 \\
\hline p-Value & $0.0092 * * *$ & $0.0092 * * *$ & $0.0132 * *$ & $0.0096^{* * *}$ & $0.0068 * * *$ & $0.0081 * * *$ & $0.0276 * *$ \\
\hline
\end{tabular}

To conclude, as with any event study without a large number of observations, the result of our JFE paper can be expected to be sensitive to the removal of a small number of observations, especially if such removal is designed in a strategic way. We have explained that some of the removals urged by Amihud and Stoyanov are questionable, non-standard, or unwarranted. Nonetheless, examining the consequences of all the various removals they have suggested, we have found that the results remain largely consistent with the results and conclusions of our JFE paper. 


\section{Alternative Specifications of the "Treated" Group}

Finally, we note that our paper was written using a very conservative window of "late" meeting firms, which resulted in a relatively small set of treatment firms. We now turn to examine an alternative definition, which expands the set of firms considered treated. As in the JFE paper, our analysis is based on comparing two types of firms with "off-season" meetings (i.e., not during the standard April-to-June proxy season) - the "early" January-to-Marchmeeting firms versus late-meeting firms. However, we now include, in the set of late-meeting firms, all the firms with post-season meetings. That is, we add, to the original group of (September-to-December-meeting) treated firms, those firms with meetings in July and August. Based on this definition, our sample now includes 110 treatment firms.

Table 3: Removing Observations, Larger Window

\begin{tabular}{|c|c|c|c|c|c|c|c|}
\hline Panel & $\begin{array}{l}\text { oled } \\
\qquad \begin{array}{l}(1) \\
\text { Baseline }\end{array}\end{array}$ & $\begin{array}{c}(2) \\
\text { M\&A } \\
\text { Firms }\end{array}$ & $\begin{array}{c}(3) \\
\text { ARG }\end{array}$ & $\begin{array}{c}(4) \\
\text { ASB\& } \\
\text { EONC }\end{array}$ & $\begin{array}{c}(5) \\
\text { Top \& } \\
\text { Bottom 1\% }\end{array}$ & $\begin{array}{c}(6) \\
(2)-(5)\end{array}$ & $\begin{array}{c}(7) \\
(6)+\mathrm{DS} \\
\text { Firms }\end{array}$ \\
\hline Treat & $\begin{array}{c}97.249 * * * \\
(31.22)\end{array}$ & $\begin{array}{c}97.270 * * * \\
(31.28)\end{array}$ & $\begin{array}{c}88.513^{* *} \\
(33.24)\end{array}$ & $\begin{array}{c}92.376^{* * * *} \\
(31.99)\end{array}$ & $\begin{array}{c}90.986 * * * \\
(33.43)\end{array}$ & $\begin{array}{c}83.345^{* *} \\
(36.33)\end{array}$ & $\begin{array}{l}61.348^{*} \\
(31.24)\end{array}$ \\
\hline Event II & $\begin{array}{c}37.65 \\
(41.92)\end{array}$ & $\begin{array}{c}36.81 \\
(42.37)\end{array}$ & $\begin{array}{c}36.16 \\
(42.26)\end{array}$ & $\begin{array}{l}22.949 \\
(33.23)\end{array}$ & $\begin{array}{c}34.050 \mathrm{a} \\
(21.51)\end{array}$ & $\begin{array}{l}29.702 \\
(22.19)\end{array}$ & $\begin{array}{c}37.895 \mathrm{a} \\
(23.47)\end{array}$ \\
\hline Cons & $\begin{array}{l}-47.387 \\
(35.22)\end{array}$ & $\begin{array}{l}-46.954 \\
(35.33)\end{array}$ & $\begin{array}{l}-43.234 \\
(36.28)\end{array}$ & $\begin{array}{l}-41.869 \\
(31.03)\end{array}$ & $\begin{array}{c}-56.845^{* *} \\
(24.21)\end{array}$ & $\begin{array}{c}-51.267 * \\
(25.51)\end{array}$ & $\begin{array}{c}-49.187 * * \\
(23.45)\end{array}$ \\
\hline Ind FE & Yes & Yes & Yes & Yes & Yes & Yes & Yes \\
\hline $\mathrm{N}$ & 344 & 340 & 342 & 340 & 336 & 328 & 322 \\
\hline
\end{tabular}

Panel B: Individual Days vs. Simulation

\begin{tabular}{lccccccc} 
Event 1 & 90.471 & 90.645 & 85.001 & 92.438 & 90.976 & 88.347 & 65.537 \\
Event 2 & -104.027 & -103.896 & -92.025 & -92.313 & -91.968 & -79.318 & -58.434 \\
p-Value & $0.0064 * * *$ & $0.0064 * * *$ & $0.0087 * * *$ & $0.0087^{* * *}$ & $0.0087^{* * *}$ & $0.0119^{* *}$ & $0.0285^{* *}$ \\
\hline \hline
\end{tabular}


Table 3 replicates the analysis of Table 2 using this broader definition of treated firms. Our results are similar to those of Table 3 but, with $24 \%$ more observations, the statistical significance of the regression coefficients is more robust to the exclusion of observations. ${ }^{6}$ The results are significant in all the specifications of columns (2)-(7), with most of the specifications yielding statistically stronger results relative to Table 2. Moreover, as before, our simulations produce results that are significant at the $5 \%$ level in all (and at the $1 \%$ level in most) specifications, again with most of the specifications yielding statistically stronger findings relative to Table $2 .^{7}$

We also examine another refinement of the definition of treated firms. Under Delaware law, the board of directors may delay the date of the annual meeting as long as it does not take place more than thirteen months since the date of the preceding annual meeting. Thus, the board of directors of a firm that has a December annual meeting would be able to move to a January meeting date with relative ease, by waiting the permitted thirteen months before holding the next annual meeting. By contrast, late-meeting firms with a meeting date prior to December cannot switch to having an early-meeting date with such ease. Therefore, it could be argued that some firms with December meeting dates, even if not all, can be expected to have been affected by the Airgas rulings less than firms with late-meeting date prior to December. We therefore redo all of our tests with a revised definition of treated firms that excludes firms with a December annual meeting.

In Table 4 below we reproduce Table 3 but with December-meeting firms excluded from the set of firms that are affected by the treatment. Overall, the results in Table 4 are quite consistent with those in Table 3 but, as we expected, the estimated coefficient on Treat tended to be larger in magnitude. Results from the simulation, which also excludes December-meeting firms, are similar to but tend to be stronger than those in Table 3.

Overall, the additional robustness tests that we conducted in this section reinforce and support the conclusions in our JFE paper.

\footnotetext{
${ }^{6}$ We note that in column (7), we also follow the AS approach of only including those observations for whom there are valid returns on CRSP across the whole event window.

${ }^{7}$ For this table, we re-run the simulation exercise over non-event days using the new treatment definition.
} 
Table 4: Removing Observations, Larger Window, No December-Meeting

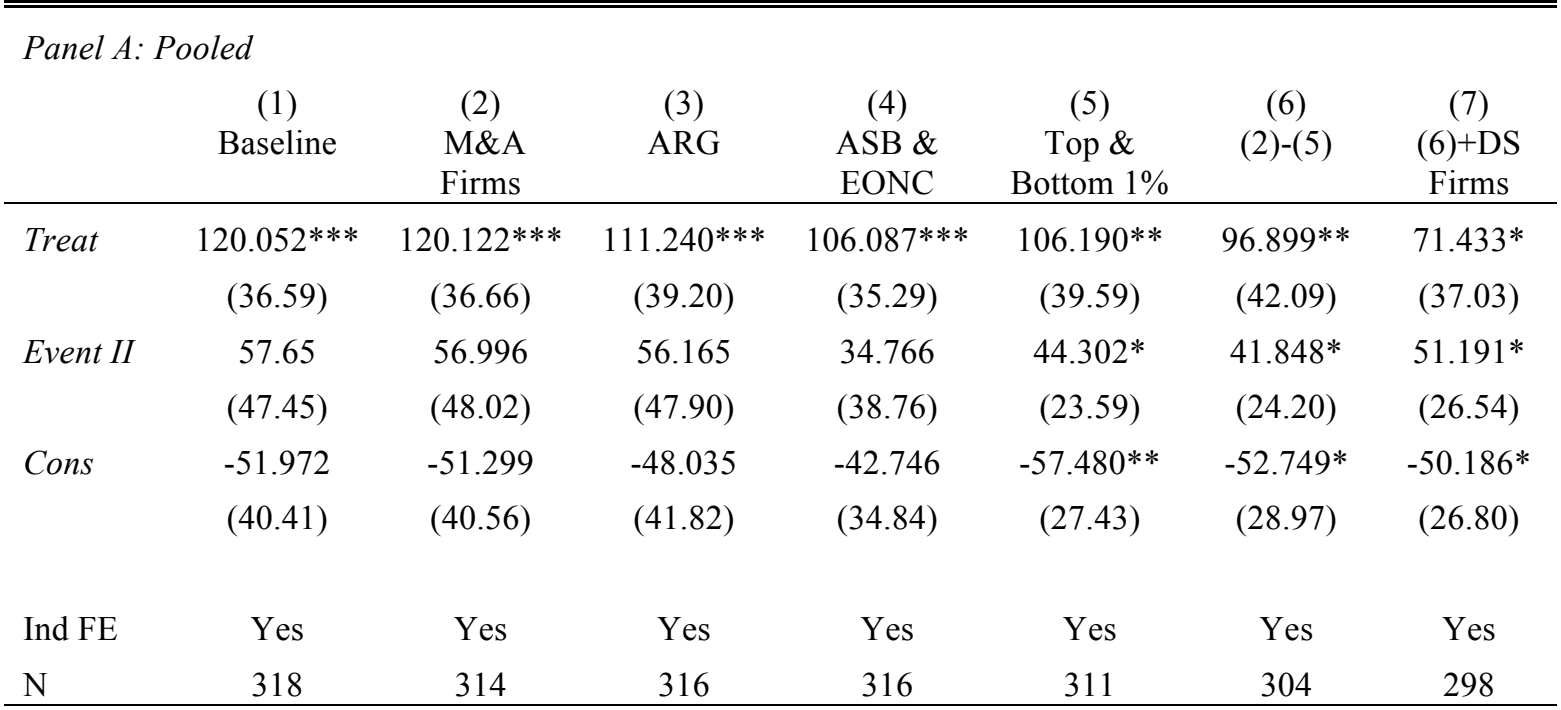

Panel B: Individual Days vs. Simulation

\begin{tabular}{cccccccc} 
Event 1 & 93.664 & 93.823 & 87.975 & 93.324 & 98.171 & 92.211 & 63.092 \\
Event 2 & -146.439 & -146.420 & -134.505 & -118.850 & -115.826 & -103.010 & -80.361 \\
$p$-Value & $0.0003 * * *$ & $0.0003 * * *$ & $0.0021 * * *$ & $0.0036 * * *$ & $0.0027 * * *$ & $0.0056^{* * *}$ & $0.0204 * *$ \\
\hline \hline
\end{tabular}

Note: This table replicates the specification of Table 3, but removes December-meeting firms. Columns (2) to (7) reflect results after removing certain observations. Cluster-robust standard errors, clustered at the six-digit GICS level, appear immediately below the coefficient estimates in parentheses. Levels of significance are indicated by $* * *$, and $* * *$ for $10 \%, 5 \%$, and $1 \%$, respectively.

\section{Replicating Amihud-Stoyanov}

In the analyses conducted in AS Table 1, they report results that exclude the two M\&A firms, the three firms that are in our Datastream sample but not in CRSP, and the delisting returns of ASB. Because AS choose to exclude ASB but not EONC, the second firm with extreme return on the second event date, therefore, the sample they examine is different than any of the samples used in the regressions in the above tables. While we do not see a reason for using the precise subsample that they chose to use, for completeness we also reran our tests results using this precise subsample. Redoing our main tests for this subsample, we are able to replicate the AS results and obtain similar coefficients and significant levels to those they report. As they report, the coefficient on Treat continues to obtain the same sign but loses its statistical 
significance and declines in magnitude. We also obtain similar results as AS by further removing ARG. ${ }^{8}$

Furthermore, when we use the refinements examined in Tables 3 and 4, we find that, by increasing the number of treatment observations using a wider window of treated firms, we continue to find statistical significance - both in the traditional regression-based tests as well as using the simulated distribution of nonevent coefficients. For example, using the AS filtering requirements for observation removal (including the removal of ARG), and expanding the definition of treated firms to include July- and August-meeting firms, we obtain a coefficient on Treat of 47.3 basis points that is significant at the $10 \%$ level using cluster-robust standard errors; and we also observe a first day coefficient of 64.9 basis points and a second day coefficient of 30.9 , which is observed only $4.4 \%$ of the time over nonevent days. Similarly, when we further sharpen our classification of "most affected" firms by removing December-meeting firms, we find similar (but marginally stronger) results both economically and statistically. Thus, when the power of our tests is strengthened, the results are statistically significant even if one were to follow precisely the sample exclusions recommended by AS, which we believe would not be the right approach.

\section{Conclusion}

This paper has examined the various ways in which AS have attempted to weaken the significance of the results of $\mathrm{CW}$. Although there are reasons to question some of their methodological suggestions, we have analyzed the consequences of following their suggested specifications and conducted additional robustness tests. Our analysis shows that the evidence is overall consistent with the results and conclusions of our 2013 paper, as well as with those of other event studies that use exogenous shocks to study the market's estimate of the value effects

\footnotetext{
${ }^{8}$ Amihud and Stoyanov refer to a treatment effect of 20 basis point as being "economically insignificant." However, note that because the first Airgas ruling only weakened the force of staggered boards, rather than fully undoing it, any estimated effect represent only a fraction of the market's perceived effect of removing staggered boards.
} 
of staggered boards. ${ }^{9}$ The AS assertion that staggered boards have "no significant effect on firm performance and value" is not supported by the evidence.

\footnotetext{
${ }^{9}$ As we stressed in our JFE paper (p. 628), our work (and the above other event studies) estimate the average treatment effect (of weakening staggered boards) for the affected firms in the sample, and thus we cannot rule out the possibility that staggered boards might have heterogeneous effects.
} 


\section{References}

Amihud, Y. and S, Stoyanov, 2015. Do staggered boards harm shareholders? Working Paper, November 2015.

Bebchuk, L.A. and A. Cohen, 2005. The costs of entrenched boards, Journal of Financial Economics 78, 409-433.

Bebchuk, L. A., A. Cohen, and A. Ferrell, 2009. What matters in corporate governance? Review of Financial Studies 22, 783-827.

Bhojraj, S., C.M.C. Lee, and D.K. Oler, 2003. What's my line? A comparison of industry classification schemes for capital market research. Journal of Accounting Research 41, 745774.

Cohen, A. and C.C.Y. Wang, 2013, How do staggered boards affect shareholder value? Evidence form a natural experiment. Journal of Financial Economics 110, 627-641.

Cremers, M., L. Litov, and S. Sepe, 2014. Staggered boards and firm value, revisited. Working Paper, July 2014.

Daines, R., 2001. Do classified boards affect firm value? Takeover defenses after the poison pill. Working Paper.

Faleye, O., 2007. Classified boards, firm value, and managerial entrenchment. Journal of Financial Economics 83, 501-529.

Frakes, M. D., 2007. Classified Boards and firm value. Delaware Journal of Corporate Law 32, 113-157.

Ge, W., L. Tanlu, and J. Zhang 2015. What are the consequences of board destaggering? Review of Accounting Studies, Forthcoming.

Guo, R., T. Kruse, and T. Nohel, 2008. Undoing the powerful anti-takeover force of staggered boards. Journal of Corporate Finance 14, 274-288.

Karakas, O. and M. Mohseni, 2015. Staggered Boards and Private Benefits of Control. Working Paper.

Kim, D., 2015. Board classification and shareholder value: Evidence from corporate law amendments. Working Paper.

Masulis, R., C. Wang, and F. Xie, 2007. Corporate governance and acquirer returns. Journal of Finance 62, 1851-1889. 